\title{
Thinking of selection and widening access as complex and wicked problems
}

Cleland $\mathrm{JA}^{1}$, Patterson $\mathrm{F}^{2}$, Hanson $\mathrm{MD}^{3}$

${ }^{1}$ Centre for Healthcare Education Research and Innovation (CHERI), Institute of Education for Medical and Dental Sciences, University of Aberdeen, Foresterhill, Aberdeen, UK

${ }^{2}$ Work Psychology Group, Derby, UK

${ }^{3}$ Department of Psychiatry, Faculty of Medicine, University of Toronto, Hospital for Sick Children, Toronto, Canada 


\section{Abstract}

\section{Objectives}

"Wicked problems" are complex in nature, have innumerable causes associated with multiple social environments and actors with unpredictable behaviour and outcomes, and are difficult to define or even resolve. This paper considers why and how the frameworks of complexity theory and wicked problems can help medical educators consider selection and widening access (WA) to medicine through fresh eyes to guide future policy and practice. We illustrate how "wickedity" can frame the key issues in this area, and then address steps that educational stakeholders might take to respond and act toward these issues.

\section{Methods}

We used the 10 properties of a wicked problem to frame common issues in the broad field of selection and WA in medicine. We drew heavily on literature from different disciplines, particularly education, and, through debate and reflection, agreed on the applicability of the theory for illuminating and potentially addressing outstanding issues in selection and WA.

\section{Results}

Framing medical school selection using the 10 properties of wicked problems is a means of shifting thinking from erroneous "simple" solutions to thinking more contextually and receptively. The wicked problem framework positions selection as a multi-causal, complex, dynamic, social problem, and foregrounds stakeholders' views and context as being highly relevant in medical school selection.

\section{Conclusions}

The wicked problem lens shifts thinking and action from seeking one elusive, objective truth to recognising the complexity of medical school selection, managing uncertainty, questioning and considering "issues" associated with medical school selection more productively. While there are criticisms of this framework, labelling medical selection as "wicked" provides original insights and genuine reframing of the challenges of this important, and high profile, aspect of medical education. Doing so in turn opens the door to different responses than would be the case if selection and widening access were simple and readily tamed. 


\section{Introduction}

Medical School selection should reliably identify whether candidates are likely to be successful in medical training and ultimately become competent clinicians.(1,2) However, despite almost a century of research little has changed in terms of increasing minority group representation (widening access) and there remains a major gap between research evidence and policy enactment in many contexts. In short, the holy grail of medical school selection has yet to be found.

Why is this the case? We believe that this is because medical school selection is highly complex. For example, most medical schools want to assess applicants against multiple attributes and qualities considered as prerequisites for an entering medical student/graduating doctor.(3-6) However, the outcomes, or goals, of selection are not static. Instead, they shift on the basis of global and national societal drivers of medical education.(7-9) These drivers include political imperatives to recruit more students from certain groups into medical school (also referred to as "widening access", or WA), to graduate doctors who will train and work in particular specialties and/or locations and to assess for relevant personal attributes as well as academic attainment. Medical schools want to know if their selection processes have "worked" but outcome measures used to evaluate selection practices are typically reductionist, largely focusing on linear relationships between measures of attainment (e.g. medical school achievements, performance in licensure exams) rather than more comprehensive (and more-difficult-to-measure) indicators such as those relating to clinical practice, typical day-today job performance and, ideally, patient health outcomes.(10)

There is no question that major changes have occurred in medical selection over the last few decades: in two linked pieces of work, Cleland et al. and Patterson et al. $(1,2)$ cogently outline the shift from reliance on references and personal statements towards using more contemporary, and theoretically-informed approaches, such as mini-multiple interviews (MMI) and situational judgement tests. Yet in spite of these significant changes in medical selection practices, the composition of the medical student body has not changed dramatically. Medicine remains dominated by certain societal groups while other, less privileged groups continue to be underrepresented.(11) There are tensions between maintaining the meritocracy of an academic elite while also achieving diversity (12), and between the institutional goals of medical schools and WA policy.(13) Views of acceptable, or otherwise, approaches to addressing such imbalances vary by country and over time (e.g., the use of quotas and targets (14), of contextualised admissions (15) or of a lottery system (16)). 
The argument above suggests that medical school selection is not simple, nor stable, does not operate within clearly defined boundaries and is influenced by the variabilities of local conditions. Consequently, we propose that an understanding of these linkages and complexity is fundamental when seeking to describe, understand and address concerns and questions related to medical selection and WA. In short, it is important to acknowledge the limitations of current reductionist views of selection and instead explicitly acknowledge medical school selection in a way that respects complexity, relationships and constant change. Only by foregrounding this can we create approaches to selection and widening access which are both fit-for-purpose and future-focused.

To develop this idea, we first provide an overview of complexity theory. Then, with reference to Greenhalgh's view that complexity theory 'is little more than a general world view at a high level of abstraction; it needs to be refined, adapted and applied in different ways for different research questions' (17), we use the framework of "wicked problems"(18) to operationalise complexity theory, and give a new perspective on medical school selection. This approach provides a way of dealing with complex issues creatively and with purpose, without assuming they are controllable, and may encourage ownership of the problems of WA and medical selection. We then address steps that educational stakeholders might take to respond and act toward the wicked problem of medical selection and WA.

\section{Complexity theory}

Complexity theory is an interdisciplinary field that has its origins in the natural sciences but its principles have been adopted by the social sciences in recent years. (19-23) Complexity theory has very many interpretations, from the stripped down analysis offered by, for example Davis and Sumara (24), to the high-level analysis provided by Doll.(25) We do not privilege any one version of complexity theory in this paper. Instead, we take the fundamental view that all complexity approaches attempt to understand change and the dynamics of systems which cannot be reduced to their parts but which are a result of the complex interactions over time of players and parts of a system, key events and actions, and the variability of local conditions.(26) Indeed, by seeking isolate measurable parts (e.g., the predictive validity of individual selection tools) we sacrifice any understanding of the dynamic nature of medical school selection. Seeing medical school selection through a complexity framework helps to avoid the temptation of reductionism (27) and provides an epistemology for understanding the interactions between structures and human agents.(28) In 
short, analysing selection from a complexity theory perspective enables us to consider uncertainty, interaction, unpredictability and non-linearity, and how things (e.g., preferred approaches to medical selection) adapt (self-organise) and evolve (emerge) over time.

\section{Wicked problems}

The term 'Wicked Problem' as stated earlier was coined by Horst Rittel (18) 40 years ago to describe "ill-defined problem sets which are too complex to be solved by rational systematic processes" (Whelton \& Ballard, 2002, p1). (29)

"Wicked" problems are complex in nature, have innumerable causes associated with multiple - and shifting - social, cultural and political environments and actors with different interpretations of the same issue, unpredictable behaviour and a lack of agreement re desirable outcomes, making them difficult to define or resolve.(30-32) Indeed, the term "wicked" denotes resistance to resolution (33) rather than something more sinister. Wicked problems are also characterised by cause and effect typically being "distant in time and space" (34)(p.782). The parallel to this in medical school selection is that selection and widening access to medicine are complex, with contradictory discourses (e.g., maintain excellence and increase diversity $(12,35,36)$ and changing requirements (e.g., select for personal attributes as well as academic aptitude) that are often difficult to recognise, let alone resolve.

Although developed over 40 years ago in the context of social planning, the "wicked problem" framework is used extensively in management and organisational science and is being adopted increasingly to examine problems in the wider field of education (37-39), including medical education. $(40,41)$ The notion of using the frame of "wicked problem" with complexity theory has also been proposed previously $(38,42,43)$ and this combination of complexity theory and the wicked problem framework has previously been applied in other fields (e.g., children and youth services (44), public policy (45), poverty (46), and business strategy (32)). The linkages between wicked problems and complexity theory has been illustrated in these studies - for example, the absence of a stopping rule for decision-making, interactions among variables and difficulties making effective interventions because of the unpredictable patterns of change. Likewise, the absence of clear solutions appears to be a component of both theories. 
Thus, the wicked problem framework shifts the focus of managing a complex issue, in this case selection and WA, from erroneously looking for a simple solution, to thinking different about how problems can be tackled. This means, for example, acknowledging subtleties and complexities rather than overlooking them, thinking about process not just outcome, and learning from apparent failures. Using this approach may allow us to develop knowledge of more legitimate solutions to selection and WA.

We present a summary of wicked problems in Table One then directly but briefly relate each of the dimensions to medical selection. Although presented as a list, these are not linear nor mutually exclusive.

Table 1: The 10 properties of a wicked problem (Adapted from Rittel and Webber, 1973 (18)).

1. There is no definitive formulation of a wicked problem

2. Wicked problems have no stopping rule

3. Solutions to wicked problems are not true-or-false, but good or bad

4. There is no immediate and no ultimate test of a solution to a wicked problem

5. Every solution to a wicked problem is a "one-shot operation"

6. Wicked problems do not have an enumerable or comprehensive set of potential solutions

7. Every wicked problem is essentially unique

8. Every wicked problem can be considered to be a symptom of another problem

9. The existence of a discrepancy representing a wicked problem can be explained in numerous ways

10. The social planner has no right to be wrong

There is no definitive formulation of a wicked problem

Rittel and Webber (18) argue that there are different ways to see a wicked problem depending on the stance of the stakeholder. Different parties may have different but equally well-defined ideas about what the problem actually is $(47,48)$, and these diverse views on the nature of a problem lead to multiple potential solutions.(49) Different stakeholders have different perspectives on what constitutes a desirable outcome in medical school selection. For example, medical schools want to select applicants who will successfully graduate. Regulators want medical schools to select not just applicants who will graduate but also those who will become competent clinicians. $(2,48,50)$ Politicians want to ensure that the supply of doctors is matched to workforce demands (10), and may also want medical school selection/students to represent the diversity of the population served (see later). 
These different perspectives do not always align, and perspectives change over time. For example, for many years, medical students in the Netherlands were selected via a grade-weighted lottery system. The political view was that, in the absence of ways to identify those who had desirable qualities beyond academic achievement at that time, a system largely based on chance was fair and equitable. This approach was broadly acceptable to many stakeholders until tensions emerged (51) and consequently changes to selection were imposed by the government.(52) Similarly, widening access to medicine with its aims of broader inclusivity and participation may be at odds with the international higher education market pressure to convey more mainstream forms of excellence and of exclusivity in selection.(12,53-55)

\section{Every wicked problem can be considered to be a symptom of another problem}

This clearly links to another characteristic of "wickedity": that every wicked problem is a symptom of another problem. Medical selection is a symptom of other problems including grade inflation, social inequalities, workforce shortages and external drivers. For example, attaining the required grades remains the first hurdle in medical admissions. However, educational attainment is linked to systemic and social factors: worldwide, students in higher socioeconomic groups outperform students in lower groups in school exit examinations.(56-58) Similarly, in many contexts, medical student numbers are tightly controlled by governments who seem to believe erroneously that there is a direct linear relationship between number of medical students selected into medical school and meeting societal healthcare needs.(10,58-60) It could be argued that the cut offs for entry are thus an artefact, a symptom of playing a numbers game, rather than a true indicator of potential to be a competent clinician, or not.

\section{Every wicked problem is essentially unique}

Medical school selection is context dependent. Different countries and localities have different needs, priorities and processes for selecting medical students. Medical schools within individual countries differ significantly in their selection policy, aims and objectives. For example, Razack and colleagues found that prestigious Canadian medical schools strongly enacted the discourse of 'excellence in scholarship' whereas those medical schools described by some as 'less prestigious' placed more value on social accountability. $(12,55)$ In a UK study, Alexander et al. (36) found that some medical schools focused their messages about WA in relation to an individual's (applicant's) social justice and mobility, but others (fewer) talked about WA being of value for the improvement of service provision and patient care. 
If context is important, then the globalization of medical education may precipitate or accentuate wickedity. For example, many countries have entered into partnerships with medical schools from the USA, Canada and the UK to import existing programmes to overseas contexts. Yet the upstream impact of one country's transplanted programmes, selection priorities and processes upon another country's prospective medical school applicant pool for these schools is unknown.

\section{Wicked problems have no stopping rule}

Rittel and Webber propose that to have any chance of actually solving a problem requires a causal explanation of the discrepancy between actual state and desired state.(18) While it might be reasonable to say that the ultimate intentions of selection are to predict who will be the most competent clinicians and who will deliver care which meets the healthcare needs of the population, what does this actually mean? As discussed earlier, it is highly likely that how we formulate what is a 'competent clinician' today will be significantly different in 20 years' time given medical education and admissions are constantly changing and evolving to reflect the needs of contemporary medical practice. $(9,61,62)$ As a result, even if we can identify the "optimal" selection process, this can only ever have a temporary life span as the 'goal posts' shift.

\section{Every solution to a wicked problem is a "one shot operation"}

Each attempt to address a particular aspect of selection may have unanticipated consequences. For example, as selection into medical school has shifted from being purely based on prior academic attainment, a new issue, how to best weigh different selection methods in the medical admissions process emerged (this also reflects the "no stopping" rule of wicked problems). In short, every change in medical selection processes has an impact.

\section{Solutions to wicked problems are not true-or-false but good or bad}

Many solutions to selecting the best candidates to study medicine have been proposed over time. Each of these solutions, or tools, have their strengths and weaknesses (2), and at different points in time, and in different contexts, may be seen as by some stakeholders as "good" or "bad" selection tools. This links back to the proposal that there is no definitive solution to a wicked problem as whether a solution is good or bad (or good enough) will reflect the stakeholder's stance.

\section{There is no immediate and ultimate test of a solution to a wicked problem}


Tame problems can be solved by choosing and applying the correct algorithm and the outcome can be determined on the spot (e.g., red and blue make purple). On the other hand, solutions to wicked problems need to be appraised over time, and cannot be appraised/assessed in advance. An example of this is where medical selection attempts to address medical workforce maldistribution (the problem) by targeting particular groups of applicants (the solution). Some institutions have a good track record in these endeavors.(63-65) However, the substantial proportion of selected candidates who do not work as desired after graduation show that selecting into medical school to address workforce issues is not a straightforward matter of "selecting candidates with $\mathrm{x}$ characteristics will lead to y outcome" (see Gorman, 2018 for a discussion of this issue(10)).

\section{Wicked problems do not have an enumerable or comprehensive set of potential solutions.}

Although well-intentioned, medical selection can often be about giving something a try on the basis of limited evidence and acceptability. This might be bringing in a new selection tool which has been devised in some other context, and perhaps evaluated on the basis of a very different population (e.g., adopting a tool which has been tried and tested with graduate entrants into a system where medical school intake is mostly students progressing directly from high school). Yet, it is also worth considering that when possible solutions are identified to select the "best" (in the eye of the stakeholder), other possibilities may not be explored.(1,13)

The existence of a discrepancy representing a wicked problem can be explained in numerous ways This reflects the earlier points that selection is linked to other problems, and that different solutions may be acceptable depending on one's perspective. For example, one stakeholder group may think that selection should shift to a lottery system because that may be perceived as 'fair' (i.e., everyone has an equal chance irrespective of their background). Another may take the opposite stance, that contextualising admissions (taking into consideration the context and circumstances in which an applicant's attainment to date has been achieved, as exemplified in the concept of "distance travelled" (see earlier), is wholly necessary to compensate for inequalities in attainment linked to social and systems factors. Different stakeholders will have different worldviews depending on their beliefs and positions in respect to aspects of selection. Rittel and Webber (18) state that the "worldview" of the stakeholder is the strongest determining factor in explaining a discrepancy and therefore in resolving a wicked problem.

\section{The social planner has no right to be wrong.}


Finally, the very nature of wicked problems and wicked solutions means that the individuals deciding solutions (the admissions committee/lead) must live with the consequences (e.g., introducing a new selection process). At a local level, the buck stops with one individual, probably the admissions lead, even if any "solution" will have emerged from the wider context of practice, policy and research, and will have to be ratified by other members of the medical school.

\section{Responding to medical selection as a wicked problem}

Wicked problems require wicked solutions. Framing medical school selection as a complex wicked problem shifts thinking from finding an overly "narrow" solution (66) to thinking more contextually and receptively. Taking into account the importance of context when trying to understand and address complex and wicked problems is important. One medical school may look very like another superficially, leading to the temptation to lift a selection "solution" from one context and roll it out in another context. However, is a solution in one context readily suitable for another context?

There are several potentially useful approaches to addressing this. Acknowledging that each medical school has a unique space and place (67), and the relationships, dynamics and interactions between people and systems will vary because of context, may encourage more reflective discussions about selection, and acceptance that one size (of selection) does not fit all. In other words, predictive validity and other evidence of relationships and causality between admissions and performance are important but these are only part of a complex canvas (42) of medical selection, a canvas where stakeholder views and context are as relevant as psychometrically robust tools. In fact, Rittel later articulated that 'dealing with wicked problems is always political' (Protzen and Harris, 2010, p. 161).(68) To illustrate this, we provide a case study (Box 1) which describes a selection problem, one which the wickedity framework was helpful in assisting understanding and responding.

\section{Box 1 Case study around here}

Acknowledging the wider political and social aspects is helpful when considering how research can help to address wicked problems in medical selection and widening access. It suggests, for example, the need to seize windows of opportunity when researchers can brief decision-makers on the importance of research studies for policy and practice. This has been very apparent in the UK, where recent reports from the Social Mobility and Child Poverty Commission highlighted that medicine had fallen behind other subjects in ensuring fair access. $(69,70)$ To address this gap, the UK 
Medical Schools Council launched the Selecting for Excellence project, the aim of which was to provide a body of evidence which medical schools can use to ensure that they are selecting candidates who will make excellent doctors - no matter their backgrounds. (71) The (independent) research commissioned by this project directly fed upwards, to inform UK policy and provide advice on evidence-informed practice. This process also emphasised the role of translational research, research which bridges the gap between scholarship and its application to selection policy and practice. In short, timing and responsiveness are important with wicked problems.

Our next point in considering how to respond to medical selection as a wicked problem relates to adaptability and flexibility. Medical school admission committees exist to solve what we would define as taming their local priority problem - the selection each year of the incoming medical school class. Selection, in our experience of "hands-on" involvement with the admissions process (as previous Admissions Associate Dean/Director [MH] and Admissions Selector [JC]), is commonly viewed as a one-off, annual task (or more specifically as one which may not be revisited or evaluated for a number of years after a "solution" has been identified). However, it may be helpful to consider medical school selection more as a "circular process involving continuous learning, adaptation and improvement, with policy changing in response to implementation as well as vice versa" (Mulgan \& Lee 2001, p. 4) (72) This approach fits well with the repetitive nature of admissions cycles, enabling ready evaluation of changes. Shifting towards a more process-focused, adaptive model of selection may also facilitate flexibility and responsiveness to changes in the external environment. One concrete suggestion related to this, is to encourage research exploring how change and innovation (e.g., adopting new selection processes or tools) is enacted within localities and how new practices are then replicated or translated into other contexts. "Innovation" may be embraced enthusiastically but what are the underpinning beliefs, motivations and political forces that either sustain the status quo, or encourage change? The research that exists on this topic indicates that individual institutions uniquely enact a selection policy (or policies) within the context of their national or state-based regulations, their own history, mission and goals, and stakeholder organisations. (13)

Our third suggestion is to bring multiple stakeholders (see earlier), and their potentially conflicting views of medical school selection together. Where cooperative approaches, collective inquiry and critical discussion are reported in other wicked contexts, these seem to help identify both the problem and a route map towards a response. $(73,74)$ Collaboration can take many different shapes depending on the wicked problem. In relation to selection and widening access, medical schools 
may wish to actively involve diverse contributors (e.g., government and hospital representatives, employers, parents and patients) in selection planning and decision-making rather than this being solely the remit of medical schools and/or national special interest groups which also only consist of medical educators. This kind of dialogue will include tensions, arguments and discomfort, but these may be beneficial for problem solving in the wicked context.(75)

The wider management literature suggests that effective collaboration can help address wicked problems in several ways. $(76,77)$ First, cooperation across boundaries/stakeholder groups increases the likelihood of shared understanding of the problem. $(78,79)$ Second, collaboration increases the likelihood of communication, pooled knowledge and openness to joint problem solving which in turn means that provisional "win-win" solutions to the problem are more likely to be identified and agreed upon.(80) Third, collaboration facilitates trust and commitment, which may facilitate solution implementation: parties are more likely to have agreed on the next steps as well as how to put them into practice. $(81,82)$ In medical selection, this may mean joining up governments, patients and medical schools to work together to consider how best to align their relative priorities. Given the complexity of collaboration, medical school admissions committees may also benefit from breaking selection and widening access "problems" down to manageable chunks ("fragments"(83)) that may help identify areas where collaborations and shared understanding may be most likely to be achieved. Collaborative efforts to solve smaller issues may offer a means of untangling the larger problem and reducing uncertainty about specific issues, which otherwise prove to be a significant barrier. In other words, while a definitive solution to a wicked problem is unlikely, "partial and provisional responses" are realistic and can help manage complex situations (Head and Alford, 2015, p. 733).(84) This approach encourages incremental changes and 'small wins' (85) along the pathway of better managing wicked problems.(86)

Fourth, those working in selection can draw on approaches from other disciplines to help address issues. Design thinking, for example, is a methodology which is considered especially useful with wicked problems (87). For wicked problems, the general thrust of the problem may be clear (e.g., the need to increase the diversity of medical students). However, clarifying how best to do this is problematic, for the reasons set out earlier. Design thinking is solution-focused and action-oriented towards creating desired outcomes, and draws on complexity as a source of creativity rather than problematic in itself $(88,89)$. This kind of thinking, thinking which encourages innovation and change, is yet to be applied in medical selection and widening access. 
Finally, as examples of collaboration to solve the issues, UKMED (90) and similar datasets in other countries allow researchers to harness large-scale, longitudinal, quantitative data, to evaluate meaningfully the effects of different approaches to selection on individual outcomes. However, in terms of acknowledging "wickedity", these studies should be coupled with qualitative, processfocused studies that examine context, stakeholder views and the influence of the wider, political arena, to contextualise quantitative findings, and look at patterns and interactions. For example, it may be useful to look at shifts in stability (e.g., a new admissions dean, increasing popularity of a new selection tool) and how these influence selection processes and practices. Or to look at how certain selection or widening access approaches may, or may not work, in differing cultural contexts. It may also be useful to explore the socio-economic-political forces behind why selection approaches shift over time.(91) For example, why are there significant, yet apparently culturally acceptable, differences in the way that different countries/contexts approach diversity and widening access issues? Are the selection aims and objectives of a medical school in a country over-producing doctors with the understanding that many graduates will migrate (92-94), different from those of a medical school in a country where student numbers are controlled by government on the basis of national workforce planning forecasts?

\section{Considerations}

Our perspectives on selection and widening access are drawn from our personal and mutual research and education interests, different backgrounds and training. We are all active in terms of selection and/or widening access research. Yet we all come from different disciplinary and practice backgrounds (JC is a clinical and occupational psychologist working in medical education, based in the UK, involved in selection as an MMI interviewer; $\mathrm{MH}$ is a medical doctor and educationalist based in Canada, and formerly an Admissions Associate Dean/Director; FP is an organisational psychologist involved in the design and evaluation of selection processes for various healthcare professions and in the corporate sector). We view these differences as productive and one of the gains from working in a sub-discipline which draws together people from many different professional groups.

We used a combination of the "wicked problem" framework with complexity theory as a way of shifting thinking on selection and widening access to medicine. This combination of approaches has been proposed and applied in other fields. $(32,38,42-46)$ However, we acknowledge that no individual lens or framework illuminates all issues (95), or is perfect. For example, there abound in the literature, especially the grey literature, numerous definitions of wicked problems yet there is a 
paucity of literature on their construct and conceptualisation.(96) Moreover, a recent paper by Alford and Head (97) criticised the lack of nuance in the wicked problem literature, suggesting that complex problems vary in the extent of their wickedness, and there should be a typology of wicked problems which extend to "super wicked problems". $(98,99)$ Linked to this, they state that the favoured means of tackling wicked problems - collaboration with key stakeholders - is too generic, and instead different types of collaboration may be suitable for different types of wicked problems. However, we believe that together complexity and wickedity can help re-frame issues with selection and widening access in such a way to invoke new ways of thinking about possible collaborations and solutions, even if there are only limited answers.(100)

\section{Conclusion}

In reviewing the complexity of the issues, it is clear that a one-stop, 'silver bullet' solution to medical selection is not possible. Complexity science and the framework of wickedity allow us to look at medical selection through fresh eyes. Using these lens shifts thinking and action from seeking one elusive, objective truth to recognising the dynamic, multi-level and multi-faceted aspects of medical selection policy, where managing uncertainty, acknowledging context, questioning and considering "issues" associated with medical selection are more likely to lead to productive solutions in future, especially regarding widening access. We argue that reviewing the extent to which medical selection is a wicked problem foregrounds the need for different responses and collaborative actions than would be the case if medical selection was viewed as simple or tame. Thinking with complexity and wickedity can encourage those involved with selection and widening access to move forward productively rather than engaging in fruitless attempts to change.(101)

\section{4, 734 words}




\section{Contributors}

$\mathrm{JC}$ had the original idea for the study and developed the paper in collaboration with FP and MH. JC prepared the initial draft, and all authors then contributed to redrafts. All authors approved the final paper before submission.

\section{Acknowledgements}

This work was unfunded but the ideas stem from numerous funded projects from over the years, particularly from the General Medical Council (GMC) and Medical Schools Council (MSC) of the UK. Our thanks also to the anonymous reviewers of an earlier version of this paper for their helpful feedback.

\section{Competing interests}

$\mathrm{JC}$ and FP have previously received research funding from the UKCAT Board, the Medical Schools Council and the Generla Medical Council. In addition, JC has received travel and subsistence expenses for attendance at the UKCAT Research Group meetings. FP and the Work Psychology Group design and develop the UKCAT Situational Judgement Test. MH holds an Associated Medical Services (AMS) Phoenix Fellowship Award to examine a New Health Professions Admission Model Grounded in Patient Defined Application Attributes, Processes and Policies.

\section{Ethics}

This was a review of published research and papers, and so ethics approval was not required.

\section{Acknowledgements}

The seed of this paper germinated over time, and so we acknowledge the many colleagues and funders we have worked with over the years. 


\section{Box 1: A Canadian wicked admissions problem}

This wicked problem rests with administration of the Medical College Admissions Test (MCAT); a unilingual (English) admissions standardized test in Canada, a bilingual (French and English languages) country. $(11,102,103)$ MCAT administration within this context reflects multiple properties of wicked problems.

First, there are the historical and political issues of language in Canada. In 1968, MCAT administration began on a national basis across most Canadian English-language medical schools. (104) A MCAT French version was contemplated, but not undertaken. Today, the four medical schools in the province of Quebec in which French is the predominant language assess applicants' academic readiness without the MCAT. One might therefore consider that the issue has been "solved" with Quebec's medical schools successfully assessing applicants' academic readiness without MCAT. However, a problem remains in terms of stakeholder perceptions. (105) For example, the discontinuation of MCAT use by one Quebec medical school, McGill, was criticized by its English-speaking alumni who believe McGill to be the single Quebec medical school option for their children (as the three other Quebec medical schools are unilingual French-language schools $(105)^{\prime}$.

Second, as relationships between French and English language populations are ever evolving it reflects the no stopping rule, different stakeholders' perspectives and absence of an immediate and ultimate solution. Today, language manifests itself also in terms of Canada's French-speaking minority communities outside of Quebec and these communities' limited accessibility to Frenchspeaking physicians.(107) Four of Canada's medical schools formally address recruitment and admission of French-speaking minority students within their communities (11). Other Canadian medical schools outside of Quebec that are located in proximity to French-speaking minority communities have not prioritized these communities and continue to use the MCAT. (103) Simple solutions are not the answer. For example, one of this commentary's authors ( $\mathrm{MH}$ ) proposed new accreditation standards or nation-wide bilingual admissions standardized testing as possible pathways forward to enhance admissions for French-speaking minority communities. (11) However, even if those English-language schools currently using the MCAT were to discontinue its use, these schools are not equipped from a curricular perspective to provide French-language curricula for French-speaking medical students. Adopting a wickedity framework may present alternative pathways forward. This framework enables identification of "small wins" within the national context embodied by those schools with current admissions policies that prioritize French-speaking 
minorities. It also acknowledges efforts to foster development of French language curriculum in English language medical schools as unfolding "windows of opportunity" 


\section{References}

(1) Cleland J, Dowell J, McLachlan J, Nicholson S, Patterson F. Identifying best practice in the selection of medical students. A project commissioned by the General Medical Council (GMC). 2012; Available at: https://www.gmcuk.org/Identifying best practice in the selection of medical students.pdf 51119804.pdf.

Accessed March, 2018.

(2) Patterson F, Knight A, Dowell J, Nicholson S, Cousans F, Cleland J. How effective are selection methods in medical education? A systematic review. Med Educ 2016;50(1):36-60.

(3) Wilkinsons TM, Wilkinson TJ. Selection into medical school: From tools to domains. BMC Med Educ 2016;16(1):258.

(4) Frank J, Snell L, Sherbino J. CanMEDS 2015 Physician Competency Framework. 2015;Ottawa: Royal College of Physicians and Surgeons of Canada.

(5) Holmboe ES, Edgar L, Hamstra S. ACGME: The Milestones Guidebook. 2016; Available at: https://www.acgme.org/Portals/O/MilestonesGuidebook.pdf. Accessed 30/04, 2018.

(6) Medical Council of India. Vision 2015. 2011; Available at:

https://old.mciindia.org/tools/announcement/MCl booklet.pdf. Accessed 30/04, 2018.

(7) Hodges BD, Lingard L. The question of competence: reconsidering medical education in the 21st century. Ithaca, New York: Cornell University Press; 2012.

(8) Cook M, Irby DM, O'Brien B. A summary of educating physicians: A call for reform of medical school and residency. San Francisco: Jossey-Bass; 2010.

(9) Frenk J, Chen L, Bhutta ZA, Cohen J, Crisp N, Evans T, et al. Health professionals for a new century: Transforming education to strengthen health systems in an interdependent world. Lancet 2010;376(9756):1923-1958.

(10) Gorman D. Matching the production of doctors with national needs. Med Educ 2018;52(1):103113.

(11) Hanson MD, Moineau G, Kulasegaram K, Hammond R:. Is Canada Ready for Nationwide Collaboration on Medical School Admissions Practices and Policies? Acad Med 2016;91(11):15011508.

(12) Razack S, Hodges B, Steinert Y, Maguire M. Seeking inclusion in an exclusive process: Discourses of medical school student selection. Med Educ 2015;49(1):36-47.

(13) Cleland JA, Nicholson S, Kelly N, Moffat M. Taking context seriously: Explaining widening access policy enactments in UK medical schools. Med Educ 2015;49(1):25-35.

(14) Lakhan SE. Diversification of U.S. medical schools via affirmative action implementation. BMC Med Educ 2003;3:6.

(15) Cleland JA, Nicholson S, Patterson F, Cousans F. The use of contextual data in medical school selection processes: a narrative synthesis. [Submitted to BMJ Open] . 
(16) Urlings-Strop LC, Themmen APN, Stijnen T, Splinter TAW. Selected medical students achieve better than lottery-admitted students during clerkships. Med Educ 2011;45(10):1032-1040.

(17) Greenhalgh T. Complexity theory and family medicine: A new symbiosis. . Swiss Journal of Family Medicine 2009;331(1).

(18) Rittel HWJ, Webber MM. Dilemmas in a general theory of planning. Policy Sci 1973;4(2):155169.

(19) Bleakley A, Cleland JA. Sticking with messy realities: how 'thinking with complexity' can inform healthcare education research. In: Cleland JA, Durning SJ, editors. Researching Medical Education Oxford: Wiley; 2015. p. 81-92.

(20) Mennin S. Self-organisation, integration and curriculum in the complex world of medical education. Med Educ 2010;44(1):20-30.

(21) Coverney P, Highfield R. Frontiers of Complexity:The Search for Order in a Chaotic World. London: Faber \& Faber; 1995.

(22) Luhmann N. Introduction to Systems Theory. Cambridge: Polity Press; 2013.

(23) Estrada E, Fox M, Higham DJ, Oppo G-. Network Science: Complexity in Nature and Technology. Dordecht: Springer; 2010.

(24) Davis B, Sumara D. Complexity and Education. Mahwah, NJ: Lawrence Erlbaum Associates; 2006.

(25) Doll WC, Fleener MJ, Trueit D, St Julien J. Chaos, Complexity, Curriculum, and Culture: A Conversation. New York: Peter Lang; 2008.

(26) Maclntosh R. Complexity and organization : readings and conversations. New York: Routledge; 2006.

(27) Walby S, Armstrong J, Strid S. Intersectionality: Multiple Inequalities in Social Theory. Sociology 2012;46(2):224-240.

(28) Callaghan G. Evaluation and Negotiated Order: Developing the Application of Complexity Theory. Evaluation 2008;14(4):399-411.

(29) Whelton M, Ballard G. Wicked problems in project definition. 2002; Available at: http://www.leanconstruction.org/media/docs/WickedProblemsinProjectDefinitionIGLC10.pdf.

Accessed May, 2018.

(30) Rasio H. Health care reform planners and wicked problems: Is the wickedness of the problems taken seriously or is it even noticed at all? J Health Organ Manag 2009;23(5):477-493.

(31) Grint K. Wicked problems and clumsy solutions: the role of leadership. Clinical Leader 2008;1(2):11-15.

(32) Camillus JC. Strategy as a wicked problem. Harvard Bus Rev 2008;86(5):98-101. 
(33) Roberts N. Coping with wicked problems: the case of Afghanistan. In: Jones L, Guthrie J, Steane $P$, editors. Learning from International Public Management Reform: Part B (Research in Public Policy Analysis and Management, Volume 11 Part 2.: Emerald Publishing Group Limited; 2015. p. 353-375.

(34) Senge PM. The Leader's New Work: Building learning organizations. In: Gallos J, editor. Organization Development San Francisco: Jossey-Bass; 2006.

(35) Razack S, Lessard D, Hodges BD, Maguire MH, Steinert Y. The more it changes; the more it remains the same: A foucauldian analysis of Canadian policy documents relevant to student selection for medical school. Adv Health Sci Educ 2014;19(2):161-181.

(36) Alexander K, Fahey Palma T, Nicholson S, Cleland J. 'Why not you?' Discourses of widening access on UK medical school websites. Med Educ 2017;51(6):598-611.

(37) Jordan ME, Klienasser RC, Roe MF. Wicked problems: inescapable wickedity. J Educ Teaching 2014;40(4):415-430.

(38) Krause K. Addressing the wicked problem of quality in Higher Education: theoretical approaches and implications. High Educ Res Dev 2012;31(3):285-297.

(39) Barrett JR. Wicked problems and good work in music teacher education. J Music Teach Educ 2012;21(2):3-9.

(40) Hawick L, Cleland JA, Kitto S. Getting off the carousel: exploring the wicked problem of curriculum reform. Perspect Med Educ 2017;6(5):337-343.

(41) Varpio L, Aschenbrener C, Bates J. Tackling wicked problems: how theories of agency can provide new insights. Med Educ 2017;51(4):353-365.

(42) Bore A, Wright N. The wicked and complex in education: Developing a transdisciplinary perspective for policy formulation, implementation and professional practice. J Educ Teach 2009;35(3):241-256.

(43) Wegner JW. Symposium 2009: A legal education prospectus: Law schools \& emerging frontiers reframing legal education's "wicked problems". Rutgers Law Rev 2009;61(4):867-1009.

(44) Devaney J, Spratt T. Child abuse as a complex and wicked problem: Reflecting on policy developments in the United Kingdom in working with children and families with multiple problems. Child Youth Serv Rev 2009;31(6):635-641.

(45) Australian Public Service Commission. Tackling wicked problems: A public policy perspective. 2012; Available at: http://www.apsc.gov.au/publications-and-media/archive/publicationsarchive/tackling-wicked-problems. Accessed May, 2018.

(46) Kolko J. Wicked Problems: Problems Worth Solving: A Handbook \& A Call to Action. Texas: AC4D; 2012.

(47) Briggs L. Tackling wicked problems : A public policy perspective. Available at: http://www.apsc.gov.au/publications-and-media/archive/publications-archive/tackling-wickedproblems. Accessed 18/12, 2017. 
(48) Trowler P. Wicked issues in situating theory in close-up researcerh. High Educ Res Dev 2012;31(3):273-284.

(49) Munneke L, Andriessen J, Kanselaar G, Kirschner P. Supporting interactive argumentation: Influence of representational tools on discussing a wicked problem. Comput Hum Behav 2007;23(3):1072-1088.

(50) Prideaux D, Roberts C, Eva K, Centeno A, Mccrorie P, Mcmanus C, et al. Assessment for selection for the health care professions and specialty training: Consensus statement and recommendations from the Ottawa 2010 conference. Med Teach 2011;33(3):215-223.

(51) Schripsema NR, van Trigt AM, Borleffs JCC, Cohen-Schotanus J. Selection and study performance: Comparing three admission processes within one medical school. Med Educ 2014;48(12):1201-1210.

(52) Cate OT. Medical education in the Netherlands. Med Teach 2007;29(8):752-757.

(53) Molesworth M, Scullion R, Nixon E. The marketisation of higher education and the student consumer. Abingdon: Routledge; 2011.

(54) Department of Business, Innovation and Skills (DBIS). Fulfilling our Potential: Teaching Excellence, Social Mobility and Student CHoice. 2015; Available at:

https://www.gov.uk/government/uploads/system/uploads/attachment data/file/523420/bis-16261-he-green-paper-fulfilling-our-potential-summary-of-responses.pdf. Accessed May, 2018.

(55) Razack S, Maguire M, Hodges B, Steinert Y. What might we be saying to potential applicants to medical school? Discourses of excellence, equity, and diversity on the Web sites of Canada's 17 medical schools. Acad Med 2012;87(10):1323-1329.

(56) Bowes L, Thomas L, Peck L, Nathwani T. International research on the effectiveness of widening participation. 2013; Available at:

http://www.hefce.ac.uk/pubs/rereports/vear/2013/wpeffectiveness/. Accessed March, 2018.

(57) Gorard S, Adnett N, May H, Slack K, Smith E, Thomas L. Overcoming the Barriers to Higher Education. London: Trehtham Books; 2007.

(58) Chowdry H, Crawford C, Dearden L, Goodman A, Vignoles A. Widening participation in higher education: Analysis using linked administrative data. J R Stat Soc Ser A Stat Soc 2013;176(2):431-457.

(59) European Commission: Eurostat. Statistics A-Z. Available at:

http://ec.europa.eu/eurostat/data/statistics-a-z/abc. Accessed May, 2018.

(60) Davis K, Stremikis K, Squires D, Schoen C. Mirror, Mirror, on the Wall: How the Performance of the US Health Care System Compares Internationally. 2014; Available at:

http://www.commonwealthfund.org/publications/fund-reports/2014/jun/mirror-mirror. Accessed May, 2018.

(61) Association of Faculties of Medicine of Canada. The Future of Medical Education in Canada (FMEC): A Collective Vision for MD Education. 2010; Available at: https://www.afmc.ca/future-ofmedical-education-in-canada/medical-doctor-project/index.php. Accessed March, 2018. 
(62) Carraccio C, Wolfsthal SD, Englander R, Ferentz K, Martin C. Shifting paradigms: From flexner to competencies. Acad Med 2002;77(5):361-367.

(63) Rourke J. How can medical schools contribute to the education, recruitment and retention of rural physicians in their region? Bull WHO 2010;88(5):395-396.

(64) Ray RA, Woolley T, Sen Gupta T. James Cook University's rurally orientated medical school selection process: Quality graduates and positive workforce outcomes. Rural Remote Health 2015;15(4).

(65) Worley P, Martin A, Prideaux D, Woodman R, Worley E, Lowe M. Vocational career paths of graduate entry medical students at Flinders University: A comparison of rural, remote and tertiary tracks. Med J Aust 2008;188(3):177-178.

(66) Clarke M, Stewart J. Handling the Wicked Issues - A Challenge for Government. University of Birmingham, School of Public Policy Discussion Paper 1997.

(67) Hawick L, Kitto S, Cleland J. Curriculum reform: the more things change, the more they stay the same? Perspect Med Educ 2016;5:5-7.

(68) Protzen J, Harris D. The Universe of Design: Horst Rittel's Theories of Design and Planning. London: Routledge; 2010.

(69) Milburn A, Cabinet Office. Fair access to professional careers. A progress report by the independent reviewer on social mobility and child poverty. 2012; Available at:

https://www.gov.uk/government/uploads/system/uploads/attachment data/file/61090/IR FairAcc ess acc2.pdf. Accessed March, 2018.

(70) Milburn A. University Challenge: How Higher Education Can Advance Social Mobility. 2012; Available at:

https://www.gov.uk/government/uploads/system/uploads/attachment data/file/80188/HigherEducation.pdf. Accessed March, 2018.

(71) Medical Schools Council, Selecting for Excellence Executive Group (SEEG). Selecting for excellence: final report. 2014; Available at: https://www.medschools.ac.uk/media/1203/selectingfor-excellence-final-report.pdf. Accessed March, 2018.

(72) Mulgan G, Lee A. Better Policy Delivery and Design: A Discussion Paper. UK Cabinet Office, Performance and Innovation Unit 2001.

(73) Conklin J. Dialogue Mapping: Building Shared Understanding of Wicked Problems. London: Wiley; 2005.

(74) Robert N. Coping With Wicked Problems. Department of Strategic Management Working Paper. Naval Postgraduate School, Monterey, California 2000.

(75) Jordan ME, Babrow AS. Communication in Creative Collaborations: The Challenges of Uncertainty and Desire Related to Task, Identity, and Relational Goals. Commun Educ 2013;62(2):210-232. 
(76) Ansell C, Gash A. Collaborative governance in theory and practice. J Public Adm Res Theory 2008;18(4):543-571.

(77) Head BW. Assessing network-based collaborations Effectiveness for whom? Public Manage Rev 2008;10(6):733-749.

(78) Bentrup G. Evaluation of a collaborative model: A case study analysis of watershed planning in the Intermountain West. Environ Manage 2001;27(5):739-748.

(79) Pahl-Wostl C, Hare M. Processes of social learning in integrated resources management. J Community Appl Soc Psychol 2004;14(3):193-206.

(80) Agranoff R. Managing within networks: Adding value to public organizations. Washington DC: Georgetown University Press; 2007.

(81) Koppenjan J, Klijn E. Managing uncertainties in networks. London, UK: Routledge; 2004.

(82) Mandell M. Getting results through collaboration: Networks and network structures for public policy and management. Connecticut, MT: Quorum Books; 2001.

(83) Conklin J. Wicked Problems and Social Complexity. 2001-2010; Available at: http://cognexus.org/wpf/wickedproblems.pdf. Accessed May, 2018.

(84) Head BW, Alford J. Wicked Problems: Implications for Public Policy and Management. Adm Soc 2015;47(6):711-739.

(85) Weick KE. Small wins: Redefining the scale of social problems. Am Psychol 1984;39(1):40-49.

(86) Head BW. How can the public sector resolve complex issues?: Strategies for steering, administering and coping. Asia-Pac J Bus Adm 2010;2(1):8-16.

(87) Kimbell L. Rethinking design thinking: Part I. Design and Culture 2011;3(3):285-306.

(88) Brown T. Change by design . New York: Harper Collins; 2009.

(89) Beacham C, Shambaugh N. Translating design thinking for scientists. Psychology of Thinking; 2011. p. 155-169.

(90) Dowell J, Cleland JA, Fitzpatrick S, McManus C, Nicholson S, Oppé T, et al. The UK Medical Education Database (UKMED) What is it? Why and how might you use it? . BMC Medical Education 2018;18(6).

(91) Monroe A, Quinn E, Samuelson W, Dunleavy DM, Dowd KW. An overview of the medical school admission process and use of applicant data in decision making: What has changed since the 1980s? Acad Med 2013;88(5):672-681.

(92) Bailey N, Mandeville KL, Rhodes T, Mipando M, Muula AS. Postgraduate career intentions of medical students and recent graduates in Malawi: A qualitative interview study. BMC Med Educ 2012;12(1). 
(93) Kizito S, Mukunya D, Nakitende J, Nambasa S, Nampogo A, Kalyesubula R, et al. Career intentions of final year medical students in Uganda after graduating: The burden of brain drain Career choice, professional education and development. BMC Med Educ 2015;15(1).

(94) Suciu M, Popescu CA, Ciumageanu MD, Buzoianu AD. Physician migration at its roots: A study on the emigration preferences and plans among medical students in Romania. Hum Resour Health 2017;15(1).

(95) Bordage G. Conceptual frameworks to illuminate and magnify. Med Educ 2009;43(4):312-319.

(96) Marshak RJ. Reflections on wicked problems in organizations. J Manage Inq 2009;18(1):58-59.

(97) Alford J, Head BW. Wicked and less wicked problems: A typology and a contingency framework. Policy Soc 2017;36(3):397-413.

(98) Lazarus RJ. Super wicked problems and climate change: Restraining the present to liberate the future. Cornell Law Rev 2009;94(5):1153-1233.

(99) Levin K, Cashore B, Bernstein S, Auld G. Overcoming the tragedy of super wicked problems: Constraining our future selves to ameliorate global climate change. Policy Sci 2012;45(2):123-152.

(100) Peters BG. What is so wicked about wicked problems? A conceptual analysis and a research program. Policy Soc 2017;36(3):385-396.

(101) Whitehead CR, Hodges BD, Austin Z. Captive on a carousel: Discourses of 'new' in medical education 1910-2010. Adv Health Sci Educ 2013;18(4):755-768.

(102) Bandiera G, Maniate J, Hanson MD, Woods N, Hodges B. Access and Selection: Canadian Perspectives on Who Will Be Good Doctors and How to Identify Them. Acad Med 2015;90(7):946952.

(103) Eskander A, Shandling M, Hanson MD. Should the MCAT exam be used for medical school admissions in Canada? . Academic Medicine 2013;88(5):572-580.

(104) Nelson-Jones R, Fish DG. MCAT performance of Canadian and landed immigrant applicants to Canadian medical schools, 1968-1969. . Academic Medicine 1970;45(4):210-219.

(105) reiter H, Aalamian A. External review of the Office of Admissions, Equity and Diversity program, Faculty of medicine, McGill University. Available at:

ttps://www.mcgill.ca/medadmissions/files/medadmissions/mcgill external review 2013 admission s office final.pdf. Accessed 18/04, Accessed 2018.

(106) Kondro W. McGill Scuttles MCAT. . Canadian Medical Journal 2010;182(13):E670.

(107) The Association of Faculties of Medicine of canada (AFMC). Development of French-speaking medical human resources in Francophone minority communities in Canada. Available at: https://afmc.ca/medical-education/franco-doc. Accessed 24/04, 2018. 